\title{
Reclamar y construir los paisajes comunales: Los devasos de Ciudad Rodrigo en la Edad Media
}

\author{
INAKI Martín Viso y JuAN IgNacio García HeRnándeZ
}

\begin{abstract}
PALABRAS CLAVE: comunales, sacralización, Edad Media, Ciudad Rodrigo.
\end{abstract}

CÓDIGOS JEL: Q15, Q24, Q57, R14.

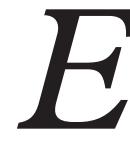

Iste artículo se centra en el análisis de los mecanismos de creación y reclamación de áreas de uso colectivo en la Edad Media, a través del caso de los devasos de Ciudad Rodrigo. Se trata de un conjunto de espacios destinados preferentemente al pasto del ganado y a la recolección de leña, a los que tenían acceso los habitantes de la villa de Ciudad Rodrigo y los vecinos de las aldeas adyacentes (comarcanos). El uso combinado del registro arqueológico y de las fuentes escritas, aplicado a los siglos XI al XV, ha permitido observar los medios de reclamación de los derechos comunales sobre esos espacios. Se plantea la hipótesis de que se utilizaran inicialmente estrategias de sacralización mediante enterramientos que vinculaban el territorio a los antepasados que más tarde se construyeran para ese fin edificaciones con funciones religiosas, pequeñas iglesias que no fueron parroquias. Esta utilización de lo sagrado coexistió con la progresiva identificación de los devasos como propiedades concejiles como consecuencia de la afirmación del poder del concejo de Ciudad Rodrigo. 


\title{
Claiming and creating common landscapes: The devasos of Ciudad Rodrigo in the Middle Ages
}

\author{
KEYWORDS: commons, sacralization, Middle Ages, Ciudad Ro- \\ drigo.
}

JEL CODES: Q15, Q24, Q57, R14.

is paper focuses on the analysis of the ways which areas of collective use were
created and claimed in the Middle Ages, through the case of the devasos of Ciu-
dad Rodrigo. They were lands used preferentially to the grazing of cattle and to the collection of firewood; the inhabitants of the town of Ciudad Rodrigo as well as the neighbours of the villages that surrounded those areas had rights of entitlement to access. The means of claiming communal rights over those spaces between eleventh and fifteenth centuries have been studied thanks to a combination of archaeological record and written sources. The main hypothesis is the use of a claiming strategy based on sacralisation. First, burials linked the territory to the ancestors during early Middle Ages, and after the construction of buildings with religious functions, small churches that were not parishes, would have been a key to preserve the commons. Those politics of the sacred coexisted with the progressive identification of the devasos as properties of the council as a result of the affirmation of the power of the town of Ciudad Rodrigo.

Recepción: 2020-03-05 - Revisión: 2020-07-16 - Aceptación: 2020-08-07

Iñaki Martín Viso [orcid.org/0000-0002-1720-0821] es profesor titular de Historia Medieval. Dirección para correspondencia: Departamento de Historia Medieval, Moderna y Contemporánea, Facultad de Geografía e Historia, Universidad de Salamanca, cl Cervantes, s/n, 37002 Salamanca (España). C. e.: viso@usal.es

Juan Ignacio García Hernández [orcid.org/0000-0002-3461-8955] es arqueólogo profesional. Dirección para correspondencia: Arqueoart, cl Ribera del Puente, 26, 1. ${ }^{\circ}, 37008$ Salamanca (España). C. e.: arqueoart@hotmail.com 


\section{USOS COMUNALES Y CONOCIMIENTO LOCAL}

Los espacios de aprovechamiento comunal constituyeron un componente relevante de los paisajes agrarios medievales (Genicot, 1993). En los últimos años ha habido un impulso provocado por la utilización de las categorías y reflexiones de Elinor Ostrom (1990) al mundo medieval y moderno (De Moor, Shaw-Taylor \&Warde, 2002; Oosthuizen, 2013; De Moor, 2015; Curtis, 2016; De Keyzer, 2018). Estos estudios se han centrado en aspectos como la gestión de los derechos sobre los recursos colectivos, la relevancia económica de tales recursos y la variable medioambiental. Por su parte, el medievalismo hispano dispone de un amplio bagaje de investigaciones que han estudiado específica o tangencialmente este tipo de recursos, pero se ha incidido sobre todo en la agresión señorial (Pastor, 1980; García de Cortázar, 1988) y, en especial, en las usurpaciones bajomedievales (Cabrera, 1978; Argente del Castillo, 1991; Carmona, 1995; Plaza de Agustín, 2015; García Oliva, 2017). Aunque algunos trabajos sobre el periodo altomedieval han subrayado el papel de los espacios comunales dentro de la organización aldeana y, por tanto, los han relacionado con un papel activo de los campesinos (Larrea, 2003-2004; Carvajal, 2017), el énfasis se ha puesto en las propiedades concejiles tardomedievales y en sus vinculaciones con las dinámicas sociopolíticas urbanas. En este contexto, la conexión entre estos recursos y determinados discursos y prácticas políticas en el ámbito concejil se revela como un eje fecundo (Monsalvo, 2004).

Aunque los caminos recorridos en el norte de Europa y en la Corona de Castilla no han sido idénticos, en ambos casos han permitido llegar a resultados de enorme interés. Sin embargo, salvo excepciones referidas al mundo moderno (Wood, 2013), no se ha considerado suficientemente la agencia de los campesinos en la creación y mantenimiento de estos recursos. Son las elites y los grupos dominantes los que protagonizan esos relatos. Sin duda, esa es una parte muy importante de la realidad, pero no toda ella. El conocimiento local de los habitantes que residían en el entorno era clave (Escalona, 2019), ya que eran quienes aprovechaban de manera directa esos recursos y gestionaban los usos cotidianos, vigilando cualquier abuso. Los límites de estos espacios eran conocidos por los lugareños, pero sin que mediara necesariamente un acto escrito. La razón estribaba en que tales usos no emanaban de una decisión jurídica, ni podían formar parte de una donación o una compraventa: por definición, eran derechos inalienables, cuya memoria se hundía en un pasado remoto. Registrada en la memoria colectiva, esa existencia atemporal podía ser útil en la argumentación concejil de sus derechos, aunque en realidad fuera una construcción discursiva urbana a partir de una vivencia colectiva campesina (Jara, 2001-2002). Las disputas sobre quiénes poseían derechos de uso no podían resolverse a través del testimonio escrito, por lo que eran frecuentes las pesquisas e incluso las ordalías (Martín Viso, en prensa). Pero también había sitio para estrategias de reclamación ba- 
sadas en el consenso y fijadas en el territorio. El análisis de las necrópolis de tumbas excavadas en la roca en la sierra de Ávila ha revelado su posible conexión con usos comunales ganaderos que afectaban a varias comunidades gracias al recuerdo de los ancestros (Blanco \& Martín Viso, 2016).

Este último ejemplo nos pone de manifiesto cómo la reclamación de los derechos sobre espacios comunales pudo generar paisajes dotados de una especial significación para quienes los utilizaban. Las estrategias pudieron ser muy diversas, pero confluían en un conocimiento local que podía plasmarse en una serie de marcadores físicos que proclamaban dónde estaban los recursos comunales y quiénes podían acceder a ellos. Este artículo se pregunta acerca de las estrategias de reclamación sobre espacios de uso colectivo y, en particular, sobre aquellas que diseñaron los habitantes locales y los campesinos, más allá de las definiciones jurídicas de propiedad. Estas formaban un entramado legal eficaz, pero estaban en manos de instituciones y grupos sociales generalmente externos a los apropiadores que disfrutaban cotidianamente de esos bienes y que poseían sus propios códigos para definir y concebir las áreas de uso colectivo. Nos preguntamos por la existencia de recursos culturales al servicio de una agencia social campesina generalmente poco tratada y su relación con otros recursos elaborados desde instancias de poder. Estas estrategias se basaban en un conocimiento local, por lo que fueron muy heterogéneas: no existía un modelo estandarizado. Además, no fueron estáticas, sino que se modificaron a lo largo del tiempo. Formaban parte de una serie de decisiones de alcance local que podemos identificar como micropolíticas, es decir, un conjunto de prácticas políticas de pequeña escala y de base consuetudinaria. El objetivo no era tanto la defensa de un modelo social igualitario como la preservación de la cohesión del colectivo, cuyos miembros podían acceder a unos mínimos necesarios y decentes para su subsistencia (Curtis, 2016). Por tanto, pueden englobarse en una «economía moral» que buscaba la inserción de las actividades productivas en un marco dotado de una serie de valores sociales (Scott, 1976; Thompson, 1995: 384-388).

\section{LOS DEVASOS DE CIUDAD RODRIGO: UN ACERCAMIENTO AL CASO DE ESTUDIO}

Estas reflexiones generales encuadran el caso de estudio que se pretende analizar: los devasos de Ciudad Rodrigo. Se trataba de un conjunto de espacios de uso colectivo característicos de la Tierra de Ciudad Rodrigo, es decir, el espacio rural sometido al control del Concejo de dicha villa, definidos por la presencia de un doble nivel de derechos de uso de carácter mancomunal: por un lado, los habitantes de las aldeas inmediatas a un devaso podían acceder a él, es decir comarcar-de hecho, se denominaba a los vecinos co- 
marcanos-; por otro, los habitantes de la villa de Ciudad Rodrigo también disponían de derechos sobre ellos, es más, podían disfrutar de cualquiera de los devasos, mientras que los comarcanos únicamente poseían derechos sobre un devaso concreto. No es un patrón específico del área mirobrigense, ya que hay casos semejantes, como los echos y alixares, que pertenecían al Concejo de Ávila, o a las áreas de pasto bajo control del Concejo de Salamanca en la sierra Mayor (Monsalvo, 2007). Se enmarcan, además, en una región, la Extremadura del Duero (es decir, en las comarcas situadas en los territorios de la meseta al sur de dicho río), donde sobresalían los amplios espacios de aprovechamiento comunal, que funcionaban como propiedades concejiles (Barrios, 1983; Villar, 1986: 149153; Asenjo, 1986, 1999; Diago, 1990).

Los devasos - un término de origen y significado desconocidos, por lo que podría derivar de formas culturales locales- eran espacios baldíos, terrenos sobre los que no había un aprovechamiento agrario intensivo y permanente, pero que podían ser utilizados como pasto o para la recolección de frutos. Este tipo de espacios eran abundantes en todo el sur del Duero, en especial en los límites de los concejos (Asenjo, 1986: 173; Monsalvo 2010a: 64-66). Aunque se dedicaban preferentemente al pasto del ganado, se conservan testimonios del siglo XV sobre la posibilidad de que pudieran ser cultivados temporalmente gracias a sorteos anuales, impidiendo así que se transformasen en propiedades individuales (Bernal, 1990: 125-126; Monsalvo, 2004: 255; Barrios, Monsalvo \& Ser, 1988: doc. 119). Gracias a un interesantísimo documento datado en 1376, conocemos mejor la extensión y funcionamiento de los devasos (Barrios, Monsalvo \& Ser, 1988: doc. 19). Ante las injerencias y usurpaciones llevadas a cabo por diversas personas contra los devasos, se realizó una amplia encuesta en la que numerosos testigos informaron a los jueces enviados por el Concejo de esas actuaciones irregulares, incluyendo abundantes noticias. Aunque en varias ocasiones se mencionaban amplios espacios como devasos, como es el caso de Valdeazaba o del Campo de Argañán (Bernal, 1990: 122-123), esto no implicaba la ausencia de propiedades individuales e incluso de espacios comunales aldeanos como ejidos o dehesas boyales (Monsalvo, 2007: 159-160). Los testimonios se referían al régimen de unas tierras baldías situadas en el outfield, que eran las sometidas a ese régimen colectivo. Un examen detallado del documento permite observar cómo las áreas de devaso estaban perfectamente identificadas y definidas y no componían todo el espacio agroganadero. Uno de esos casos es el de Valdeazaba, definido como un espacio situado entre Ituero de Azaba, La Alberguería de Argañán, La Alamedilla y Agualapiedra: «desde Fituero arriba fasta las Alberguerías e fasta las Alamedillas e fasta Lagualapiedra» (Barrios, Monsalvo \& Ser, 1988: doc. 19). Los testigos frecuentemente señalaban que ellos únicamente conocían los devasos más cercanos a sus aldeas. En el caso ya citado de Valdeazaba, quienes dan testimonio del lugar procedían de Fuenteguinaldo y de La Alberguería, aldeas aledañas o comarcanas, así como otro de Robleda, quizás con intereses más 
amplios. En el conjunto del documento, solo dos testigos ofrecieron informaciones que abarcaban espacios localizados por toda la tierra concejil y ambos son los únicos identificados como vecinos de Ciudad Rodrigo, en concreto Simón Alfonso y Alfonso Díaz, hijo del obispo Pedro Díaz. La conclusión es que, en la práctica, los principales usuarios de los devasos eran los habitantes de las aldeas comarcanas, y parece que la presencia concejil era un elemento superpuesto del que se beneficiaba una minoría de los habitantes de la villa.

Este magnífico texto revela la existencia de segregaciones parciales de espacios, anteriormente sujetos al régimen de devaso, que habían dado lugar a la formación de dehesas, como la del Águila, situada justo al norte del devaso de Valdeazaba, y de la que se dice que fue adehesada por García López no hacía demasiado tiempo, según el relato, entre otros, de Juan Rico, de Gallegos de Argañán: «oyo dezir que la Cabeça de la Aguila que fuera devaso e que Diego Garçia, fijo de Garçi Lopez, que la cobro desde quel dicho Garçi Lopez, su padre, fino e que mudara los mojones della e la defesa» (Barrios, Monsalvo \& Ser, 1988: doc. 19). Esta presión sobre estos espacios mancomunales concejiles para su conversión en propiedades privadas (términos redondos), sobre todo en lugares de escasa población, fue una constante a lo largo de los siglos XIV y XV que seguía una tendencia perceptible en otros ámbitos de la Corona de Castilla (Bernal, 1990: 119; Monsalvo, 2007: 169; Martín Martín, 1990: 17-19; Asenjo, 1999: 337-343; Monsalvo, 2001). ¿Hasta qué punto era una realidad nueva producto de los cambios en este periodo? Cabe pensar que también existieron otros factores que pueden estar distorsionando nuestra percepción. Puede que estemos ante el reflejo de un incremento del interés de los concejos por hacer efectivo su control sobre unos espacios hasta entonces regidos por la costumbre local, dentro de un discurso político que los relacionaba con el bien común. Por otra parte, estos espacios solo se mostraban en la documentación en el momento en que había conflictos, ocasiones que facilitaban que el Concejo pudiera afirmar su dominio. No se pretende negar el papel de esas transformaciones, ni de las usurpaciones en buena medida cometidas por miembros de las elites concejiles, pero también por campesinos o comunidades, como en Peñaparda - ¿actuaban como free-riders o se reflejaban cambios en las prácticas colectivas debido a la creación de nuevas identidades locales (Monsalvo, 2007: 167-168)?-, sino simplemente encuadrarlas en un marco más amplio, el de la creciente preocupación concejil por el control de estas zonas; una situación que podía derivar en políticas concejiles que rompían con esos usos. Así, el Concejo mirobrigense no dudó en utilizar un antiguo espacio de devaso para promocionar la creación de una aldea, Sancti Spiritus (Bernal, 1990: 124; Barrios, Monsalvo \& Ser, 1988: doc. 119). Por tanto, no se trataba solo de la conservación de usos mancomunales, sino también de un control más directo sobre esos espacios. Una innovación relevante fue la afirmación de términos propios de las aldeas, como sucedió con Serradilla del Arroyo y Navalportillo en 1426, lo que 
implicó un cambio en la relación con los devasos (Barrios, Monsalvo \& Ser, 1988: doc. 126). Este proceso supuso la configuración de un outfield ligado a la aldea y trajo consigo una importante transformación (Monsalvo, 2012-2013: 115-118). Sin embargo, no significó la desaparición completa del régimen mancomunal, sino que alteró los equilibrios previos. Por otra parte, la segregación de partes del término concejil para su entrega a señores generó tensiones, como ocurrió con Fuenteguinaldo, aldea que tuvo que negociar la forma en que podían mantenerse sus derechos consuetudinarios sobre los devasos de Valdeazaba y Robledo en 1432 (Barrios, Monsalvo \& Ser, 1988: doc. 156). El hecho de que finalmente se acordara que se preservasen los derechos de sus habitantes nos indica la fortaleza de los lazos comarcanos, que funcionaban a un nivel inferior de los intereses concejiles.

A pesar de todas estas informaciones, ningún documento fija jurídicamente qué era un devaso y cuáles eran los usos permitidos: estamos ante prácticas consuetudinarias y derechos inalienables, cuyos testigos recurrían a la memoria, suya o de sus antepasados (Monsalvo, 2007: 159; 2010b). No obstante, la recogida de testimonios sirvió para realizar una sentencia, un acto performativo que dotaba de un nuevo contenido a esos devasos, al fijar sus límites y usos y situarlos bajo el amparo concejil (Barrios, Monsalvo \& Ser, 1988: doc. 20). Esta sí que era una novedad bajomedieval. En realidad, el origen de tales usos se perdía en el tiempo (Bernal, 1990: 117). Su existencia no procedía de un acto jurídico, que, en cambio, aparece con las sentencias de los siglos XIV y XV.

Se ha estudiado poco el origen de los aprovechamientos mancomunales en el sur del Duero, debido a la casi completa ausencia de noticias al respecto. Se acepta generalmente que fueron creados como consecuencia de las lógicas de la repoblación cristiana, cuando la amplia extensión de unos territorios semivacíos de población y los intereses ganaderos de las elites concejiles habrían favorecido la creación de mancomunales concejiles en especial en las áreas serranas, de menores capacidades agrarias (Barrios, 1983: II, 121122; Mínguez Fernández, 1982; Asenjo, 1986: 174; 1999: 326-328; Monsalvo, 2012-2113; Reglero de la Fuente, 2015). Estas causas también explicarían la génesis de los devasos de Ciudad Rodrigo (Monsalvo, 2004: 255-256), cuya integración definitiva en los reinos cristianos se produjo en la primera mitad del siglo xII, y en 1161 se consolidó como villa y obispado. Sin embargo, la temprana presencia de términos mancomunales en la documentación escrita del sur del Duero a partir de finales del siglo XI permite sospechar que era una realidad existente en el momento de la creación de las villas (Martín Viso, 2020). Los datos polínicos, que señalan la existencia de espacios deforestados convertidos en pastos en época altomedieval, parecen ir en ese mismo sentido (Blanco et al., 2015). Pero ¿puede establecerse algo semejante para Ciudad Rodrigo? Si así fuera, ¿cuáles fueron los mecanismos para reclamar los derechos de acceso a los espacios de uso man- 
comunal al margen de la sanción concejil bajomedieval? Para tratar de responder a estas cuestiones, se llevará a cabo un acercamiento al caso de estudio que combina la información escrita con la arqueológica y la palinológica, usando una estrategia ya experimentada en otros estudios de este tipo (Dalglish, 2009).

\section{ENTERRAMIENTOS, ¿Y RECLAMACIÓN DE DERECHOS SOBRE ÁREAS DE USO MANCOMUNAL?}

La documentación escrita sobre el espacio mirobrigense comienza en la segunda mitad del siglo XII, coincidiendo con la creación del obispado y la villa en 1161 (Lucas, 1997: doc. 112; Sánchez-Oro, 1997; Barrios, 2002), fenómenos asociados a la necesidad de hacer frente a la expansión del nuevo reino de Portugal (Jiménez de Rada, 1987: VII, XVIIII). A pesar de que el volumen de información no es muy abundante (apenas una veintena de textos del siglo XII dispersos en varios fondos), algunos indicios invitan a pensar en la importancia de las actividades ganaderas en este sector, como muestra que la Orden de San Juan contase con una cabaña de al menos quinientas ovejas en Ciudad Rodrigo en 1174 (Ayala, 1995: doc. 117). Pero hay también datos que avalan que Ciudad Rodrigo estaba previamente ya ocupada. En 1136, un documento conservado en el archivo de la catedral de Salamanca se data en el año en que Ciudad Rodrigo fue comprada por los salmantinos, posiblemente a Alfonso VII (Guadalupe et al., 2010: doc. 12). Si se retrocede en el tiempo, la versión ovetense o Ad Sebastianum de la Crónica de Alfonso III recoge el lugar de Agata entre aquellos que fueron atacados por Alfonso I y su hermano Fruela a mediados del siglo viII (Gil Fernández, Moralejo \& Ruiz de la Peña, 1985: Ad Sebastianum, 13). Esta cita, elaborada a finales del siglo Ix, probablemente deba entenderse como una suerte de geografía política de la meseta del Duero vista desde el reino asturiano en el momento de su expansión por esas tierras y cuando necesitaba legitimar su dominio (Escalona, 2004). A pesar de que solo disponemos de un topónimo, quizás pueda identificarse con Ciudad Rodrigo, situado sobre un espolón fluvial que domina el río Águeda, que daría nombre al lugar (Barrios, 2002: 179; Martín Viso, 2015: 50-51); pero no cabe descartar la posibilidad de que se refiera a Águeda, en la actual Portugal. Los estudios sobre algunos espacios rurales (Martín Viso et al., 2017) y sobre el análisis de las cerámicas encontradas en el área de la primitiva muralla de Ciudad Rodrigo (Centeno, 2018) señalan la existencia de un espacio ocupado ininterrumpidamente desde los tiempos posromanos, aunque posiblemente hubo numerosas transformaciones que hasta el momento pasan inadvertidas.

Los datos arqueológicos son los únicos que pueden permitirnos abrir nuevas ventanas sobre el tiempo anterior a la «repoblación» -en realidad integración política en forma 
de concejo- de Ciudad Rodrigo en 1161. Es aquí donde nos encontramos con los resultados de una pequeña intervención arqueológica preventiva realizada en el casco urbano de Ciudad Rodrigo, concretamente en la calle de Fray Diego, número 15. Se trata de una zona situada a unos quinientos metros del área amurallada, que fue urbanizada en la segunda mitad del siglo. En época moderna y durante el siglo XIX, había formado parte del denominado arrabal de San Francisco, un espacio extramuros situado al nordeste de la población y denominado así por la presencia de un convento de franciscanos. En realidad, el espacio intervenido permaneció durante ese tiempo como una zona carente de edificaciones y emplazada sobre un pequeño teso desde el que se dominaba una vaguada entre ese punto y el núcleo amurallado, pero también los terrenos, algo más elevados, que se abrían hacia el norte hasta llegar a la sierra de Torralba.

\section{FIGURA 1}

\section{Localización de la tumba de la calle de Fray Diego} en el plano actual de Ciudad Rodrigo

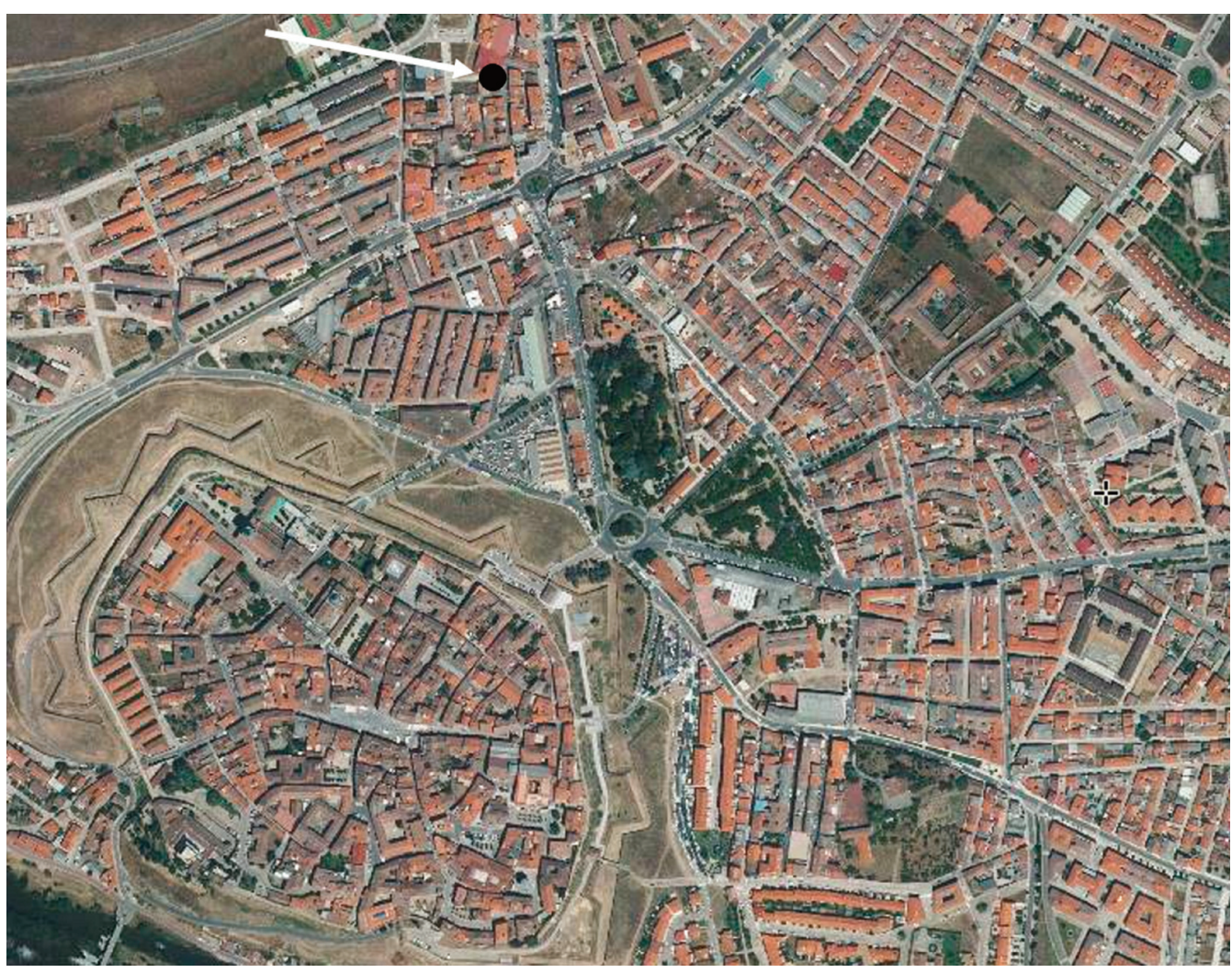

Fuente: Elaboración de Juan Ignacio García Hernández a partir de imagen de Sigpac. 


\section{FIGURA 2}

Detalle del plano Attaque et defense du couvent de St. François, siege de Ciudad Rodrigo, 1812, sobre parcelario actual

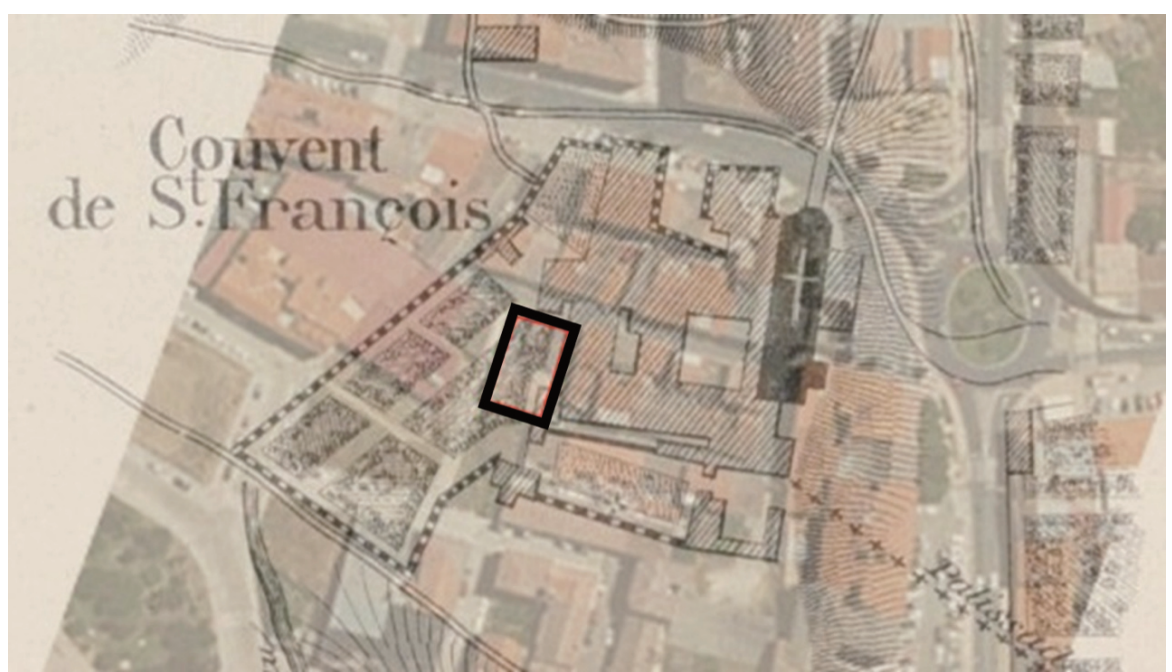

Nota: en recuadro, el solar objeto de la intervención.

Fuente: Elaboración de Juan Ignacio García Hernández sobre pano Pl. XIII. Attaque et défense du Couvent de St. franÇois (Siege de ciudad Rodrigo, 1810). En THIVAL, Louis (1880): Rôle des localités à la guerre : attaque et défense des villes ouvertes, bourgs, villages, hameaux, fermes. ATLAS /. Librarie Militaire de J. Dumaine.

La construcción de un nuevo edificio para uso de vivienda, que incorporaba un sótano/bodega, obligó a un seguimiento de las obras (García Hernández, 2018). A pesar de lo limitado de la obra, pudo constatarse la existencia de una tumba excavada en la roca, derrumbada desde antiguo, con unas medidas de 1,60 metros de largo, 0,36 metros de anchura y 0,36 metros de altura (UE 3). El arrasamiento parcial de la estructura funeraria no impidió, sin embargo, la preservación de tres cuerpos conservados fragmentariamente. Se trata de una situación poco frecuente, ya que en general este tipo de inhumaciones no ha conservado restos óseos en el centro de la península Ibérica, debido a la predilección por el uso de rocas graníticas extremadamente ácidas (Martín Viso, 2014; Rubio, 2015). Por otro lado, se ha constatado la existencia de un modelo específico de organización de espacios funerarios con tumbas excavadas en la roca en los «lugares centrales» de la Extremadura del Duero altomedieval, caracterizado por la ordenación alineada, un número relativamente elevado de inhumaciones y una localización extramuros (Martín Viso, 2016).

Gracias a la conservación de restos óseos, pudieron enviarse muestras al Laboratorio Beta Analytic para su datación. En concreto se remitieron dientes correspondientes a los 
tres inhumados. Los datos obtenidos han quedado reflejados en la Tabla 1. Los resultados son interesantes, ya que al menos uno de los individuos fue enterrado en un momento anterior a la «repoblación», posiblemente a finales del siglo XI o comienzos del siglo XII. Los otros dos individuos parecen haber sido más o menos coetáneos, a tenor de los datos, lo que no significa que fueran enterrados al mismo tiempo, sino con una separación cronológica que se escapa a los márgenes de probabilidad utilizados en el análisis de las muestras. Teniendo en cuenta los datos obtenidos, podemos movernos en torno a mediados del siglo XII, quizás poco después de la «repoblación», aunque la combinación con las fechas de la segunda de las probabilidades parece indicar cronologías más tempranas, de la primera mitad del siglo XII.

\section{FIGURA 3}

Perfil norte con la tumba de la calle de Fray Diego

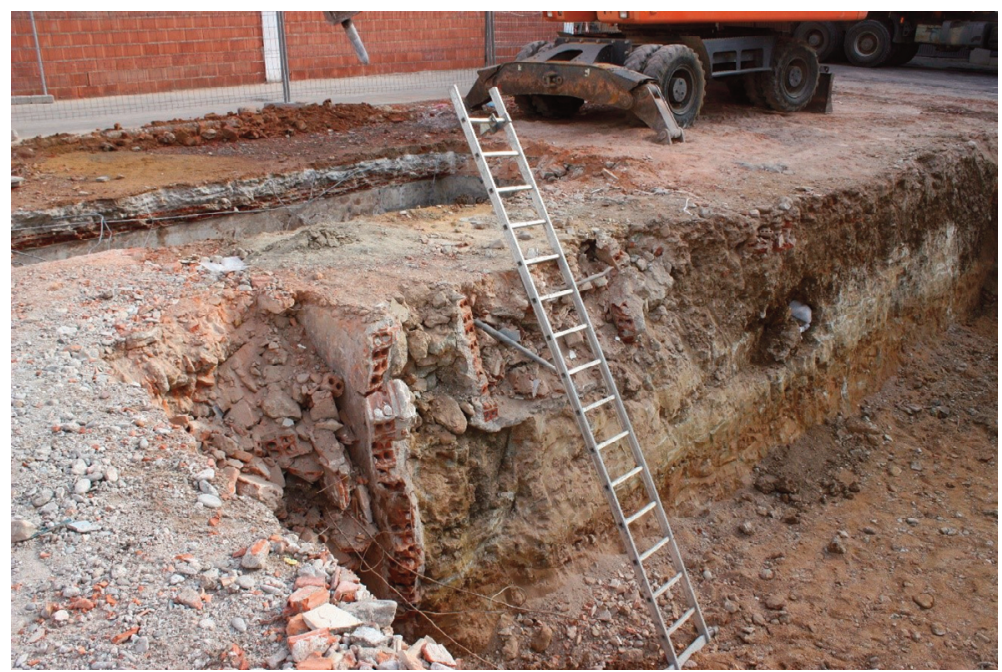

Fuente:Fotografía Juan Ignacio García Hernández.

TABLA 1

Dataciones radiocarbónicas de los restos óseos hallados en la tumba de la calle de Fray Diego

\begin{tabular}{lclccc}
\hline Num. Laboratorio & UE & Identificación & Material datado & Fecha BP convencional & Fecha cal AD \\
\hline Beta 518161 & 3 & Inhumación1 & Diente & $930 \pm 30$ & $1025-1165(95,4 \%)$ \\
Beta 518162 & 3 & Inhumación 2 & Diente & $890 \pm 30$ & $1116-1218(59,6 \%)$ \\
& & & & & $1040-1108(35,8 \%)$ \\
Beta 518163 & 3 & Inhumación 3 & Diente & $890 \pm 30$ & $1116-1218(59,6 \%)$ \\
& & & & $1040-1108(35,8 \%)$ \\
\hline
\end{tabular}


Una de las primeras lecturas que se puede hacer de estos datos es que en una época inmediatamente anterior a 1161 existía ya un espacio funerario en este lugar, situado, como se ha señalado, extramuros. Además, ese espacio funerario no se vio afectado por esa fecha considerada clave en la historia local. Todo ello viene a desmontar el mito de un lugar despoblado que fue ocupado por grupos procedentes de fuera del territorio. Una realidad que ya ha sido puesta de manifiesto previamente (Barrios, 2002; Martín Viso, 2015), pero sobre la que ahora disponemos de datos concretos. A ello se suma la constatación de que los espacios funerarios con tumbas excavadas en la roca tuvieron una larga historia, que probablemente terminó con la formación de las parroquias, iglesias bajo control diocesano en las que se concentraba la administración local de los sacramentos y que fueron ejes de la identidad aldeana, en buena medida gracias a la eclosión de los cementerios asociados a ellas (Blanco \& Martín Viso, 2016; Martín Viso, 2016). En las villas, el cambio debió producirse en tiempos relativamente tempranos en comparación con las áreas rurales, ya que se verifica en el momento de construcción de las primeras parroquias, tal y como parece observarse en Ledesma o Salamanca, por citar ejemplos cercanos (Alacet, 2006; González Echegaray, 2000; Martín Viso, 2016). Sin embargo, en el caso de la tumba hallada en la calle de Fray Diego, número 15, no podemos afirmar si hubo o no más tumbas, es decir, si nos hallamos ante un conjunto funerario amplio y no ante sepulturas aisladas; la limitada extensión de la intervención realizada impide avanzar en ese sentido. No obstante, la hipótesis que nos parece más factible es que la tumba estuviera en su momento constructivo unida a otras de las mismas características, las cuales habrían desaparecido por el uso posterior de la zona como zona de extracción de piedra, lo que provocaría la desaparición, tanto del nivel superior, donde se encontrarían fosas simples excavadas en tierra, como del nivel de tumbas excavadas en roca. Esta acción muestra la amortización del espacio funerario, quizás en relación con un proceso de creación de nuevos mecanismos de reclamación de los derechos.

Por otra parte, resulta interesante examinar la localización de este espacio funerario, adyacente al convento de los franciscanos, pero de cuyas construcciones no formaba parte. Tampoco puede relacionarse con un cementerio asociado a los frailes, ya que las fechas obtenidas no se ajustan con su creación, tradicionalmente datada en torno a 1226, aunque es una cronología más legendaria que real (Martín Benito, 2005: 351-352) y seguramente hay que pensar en un momento posterior. La documentación bajomedieval y moderna nos ofrece algunas informaciones relevantes. En el siglo XV, se documentan toda una serie de devasos concejiles en este sector y en general en los espacios situados entre Ciudad Rodrigo y la sierra de Torralba. Se trataba de aquellos devasos que componían el ejido. Ese término, aunque inicialmente se aplicaba a un espacio destinado al pasto al que tenían acceso los vecinos de un lugar adyacente, en este caso etiquetaba un extenso espacio sometido a los usos comunales de la localidad de Ciudad Rodrigo, un equivalente 
a los que vemos en otros territorios; en este caso, los comarcanos eran los propios mirobrigenses. Uno de los devasos es el de la cuesta del Obispo, donde se hallaba el prado de San Martín, citado en 1434, del que se dice que estaba "çerca del monesterio de Sanct Francisco desta dicha çibdat» (Barrios, Monsalvo \& Ser, 1988: doc. 229). A apenas cien metros de la calle de Fray Diego se encuentra la calle de San Martín, por lo que parece que el topónimo se refiere a esta parte del teso, donde existiría un espacio de uso mancomunal. De hecho, el canónigo Antonio Sánchez Cabañas, que escribió su Historia Civitatense en los años veinte del siglo XVII, recogía todavía la existencia de una parroquia de San Martín en ese lugar: "La parrochia de San Martín estuvo en el teso que llaman del Calvario, y allí se ven y descubren sus cimientos» (Sánchez Cabañas, 2001: 158). Es interesante su vinculación con la presencia de una parroquia, pero debe tenerse en cuenta que este erudito consigna un total de 23 parroquias abandonadas en Ciudad Rodrigo hacia 1627, lo que sumado a las 9 que estaban activas en ese momento da un total de 32 parroquias, un número muy desproporcionado para el lugar (ibid.: 157-159). Es probable que bajo esa etiqueta se escondan situaciones alejadas a la existencia de una parroquia como tal. Quizá la presencia de un espacio funerario, posiblemente olvidado, habría generado la idea de un área sagrada que se convirtió posteriormente en una imagen vaga de una parroquia previa, lo que estaba acorde con los parámetros de un canónigo como Sánchez Cabañas.

Por tanto, en ese espacio coexistieron un espacio funerario y un área de usos mancomunales. Esa coincidencia no parece ser puramente casual, sino que debe responder a algún tipo de realidad social. Las cronologías no concuerdan, pero es necesario tener en cuenta la tardía aparición de la documentación escrita en Ciudad Rodrigo, lo que no significa que los usos mancomunales surgieran en ese momento.Ya se ha señalado cómo las informaciones procedentes de otros puntos de la Extremadura del Duero abogan por una temprana presencia de esos mancomunales, como sucede en Sepúlveda (Vivancos, 1988: doc. 19) o en Ávila (García Andreva, 2010: doc. CCXxx.h.1). Otra cosa distinta es que fueran concebidos en términos jurídicos como propiedades concejiles. Sin embargo, una hipótesis factible es que la documentación escrita simplemente ponga a la luz una realidad existente desde largo tiempo atrás y en el momento en el que se había transformado en un bien concejil. En tal caso, puede plantearse la posibilidad de que los devasos -o al menos una parte importante de ellos- fueran, en su sentido de áreas de uso comunal, previos a la afirmación del dominio concejil. El teso de San Martín posee serios visos de haber sido uno de ellos, al coincidir topográficamente con un espacio de inhumación que se ha podido datar antes de la «repoblación». Los estudios sobre las tumbas excavadas en la roca en la comarca mirobrigense han destacado su papel como marcadores territoriales asociados al control de áreas agroganaderas (Martín Viso, 2012; Martín Viso et al., 2017; Rubio, 2015). El análisis de otros espacios del sur del Duero, como la sierra de Ávila, 
ha puesto de relieve la vinculación entre áreas de inhumación y espacios de posible uso mancomunal, que en la Baja Edad Media se redefinieron como alixares del Concejo abulense (Blanco \& Martín Viso, 2016). Es probable -aunque no es posible afirmarlo con rotundidad- que en el teso de San Martín sucediera algo semejante y que el espacio funerario, que conocemos muy fragmentariamente, hubiera servido como mecanismo de reclamación de los derechos sobre ese espacio de uso comunal o mancomunal por parte del grupo humano que allí se enterraba. El uso de los espacios funerarios como marcadores territoriales que servían para reclamar derechos de uso a los habitantes de una determinada comunidad es un fenómeno ya estudiado en otros ámbitos, en especial en sociedades que carecían de una concepción de la propiedad basada en derechos fijados por escrito (Saxe, 1971; Goldstein, 1981; Mattingly, 2008). Por supuesto, se trata de una hipótesis que precisaría un mayor número de datos para ratificarse, pero puede considerarse bastante factible si se compara con otras situaciones cercanas para las que se ha planteado esa interpretación. Si así fuera, estaríamos ante una estrategia de reclamación de derechos vinculada a los propios usuarios que tenían acceso a esos recursos.

\section{USOS COMUNITARIOS Y DERECHOS CONCEJILES EN LA BAJA EDAD MEDIA}

A partir de la segunda mitad del siglo XIII, las informaciones escritas sobre Ciudad Rodrigo comienzan a ser más numerosas, aunque hay que esperar a finales del siglo XIV para que podamos disponer de un conjunto de datos más cuantioso. No obstante, la importante dedicación ganadera del territorio mirobrigense queda reflejada en algunos documentos de la segunda mitad del siglo XII. En 1255, Alfonso X prohibió a los forasteros que acampasen con sus ganados en los terrenos acotados del término de Ciudad Rodrigo ante la queja del Concejo. En ese documento se indica que miembros de las órdenes militares y habitantes de otras villas quemaban espacios de bosque acotados posiblemente con el objetivo de rozarlos: «que omnes de ordenes e de villas que destruen un pinar e un enzinar e un rovredo de vuestra villa que son cotados con las posadas de los ganados que deben a fazer pasada por hy, e que fazen posada que non deben a fazer e están atanto que los tallan e los quemas en los destruen, por que viene grant danno a la villa» (Barrios, Monsalvo \& Ser, 1988: doc. 2). De él, pueden obtenerse varias informaciones de interés. Una se refiere al medio ambiente, en el que se contrapone la preservación de espacios de bosque en manos del Concejo de Ciudad Rodrigo, frente a los intereses posiblemente relacionados con la trashumancia -no en vano parecen ser gentes que procedían de fuera y se trasladaban por el territorio-, que buscaban crear pastos intensivos para el ganado. Se menciona un arbolado que se procura preservar como parte de las políticas implementadas por el Concejo. Estas tensiones no se hallaban cronológicamente muy distantes de 
los datos procedentes de la turbera de El Payo, localidad situada en el sur del concejo junto a la sierra de Gata. En el depósito analizado, que se emplazaba cerca de una cañada, se detecta a partir de 1330 un incremento de la actividad ganadera y de la deforestación por fuego, prácticas asociadas a la trashumancia (Silva et al., 2016) y que se asemejan a las acciones por las que se quejaba el Concejo mirobrigense. Parece factible suponer que las áreas que pretendía salvaguardar el Concejo eran semejantes a los devasos, aunque ese término no figure. En este mismo sentido, un documento de Sancho IV datado en 1289 eximía del pago de una serie de pechos a los pastores y mayorales «que tienen en guarda los ganados de los vezinos de Çibdad Rodrigo e de su termino» (Barrios, Monsalvo \& Ser, 1988: doc. 10). El documento puede leerse como un nuevo testimonio sobre el papel de la actividad ganadera y la presencia -hipotética- de áreas concejiles para el pasto de los animales.

De todos modos, la primera mención expresa a los devasos procede de la ya mencionada pesquisa de 1376 (Barrios, Monsalvo \& Ser, 1988: doc. 19). En los interrogatorios de los testigos se pone de relieve la organización de estos espacios, distribuidos por amplias zonas del territorio concejil, aunque el documento solo alumbra aquellas en las que se habían producido usurpaciones. La sentencia declaraba una serie de lugares como devasos del Concejo e incluso se habla de «devaso e conçegil» en alguna ocasión (ibid.: doc. 20). Pero es llamativo cómo los testigos a los que se interrogó únicamente utilizaron el concepto de devaso; el único de los testimonios que indica que uno de estos devasos, concretamente el de Robledo, era de los vecinos de Ciudad Rodrigo y su Tierra, procedía de Simón Alfonso, precisamente vecino de Ciudad Rodrigo y uno de esos testigos ya señalados que disponían de información sobre el conjunto de los devasos y no solo de aquel en el que comarcaba. El dato es relevante porque indica la existencia de una doble percepción de estos espacios de uso mancomunal: el de los comarcanos, asociado a prácticas locales, y el de algunos miembros de la elite mirobrigense, que incluían los derechos concejiles. Estos no se perciben, en cambio, entre los informantes locales, para los que la realidad de los devasos no se relacionaba explícitamente con el dominio concejil.

Es importante advertir que ni los usos ni el control concejil se fundamentaban en títulos jurídicos. Los testigos utilizaban su memoria, remontándose a cuarenta o cincuenta años atrás. Una situación muy semejante a la expresada por los habitantes de El Sahugo en 1419, quienes se quejaban de haber sido excluidos del devaso de Robleda, cuando habían tenido el derecho de pacer sus ganados «de diez e XX e XXX e XL e L e LX años aca e mas tiempo» (Barrios, Monsalvo \& Ser, 1988: doc. 89). En la pesquisa de 1376, únicamente un testigo menciona un hito histórico. Alfonso Esteban, de La Alberguería del Fondo, dice acordarse de que, en época de Alfonso XI (1312-1350), se libró un pleito en el que se sentenció que Robledo era devaso frente a un intento de adehesar el lugar de 
FIGURA 4

\section{Localización de los devasos de Ciudad Rodrigo en 1376}

$1)$

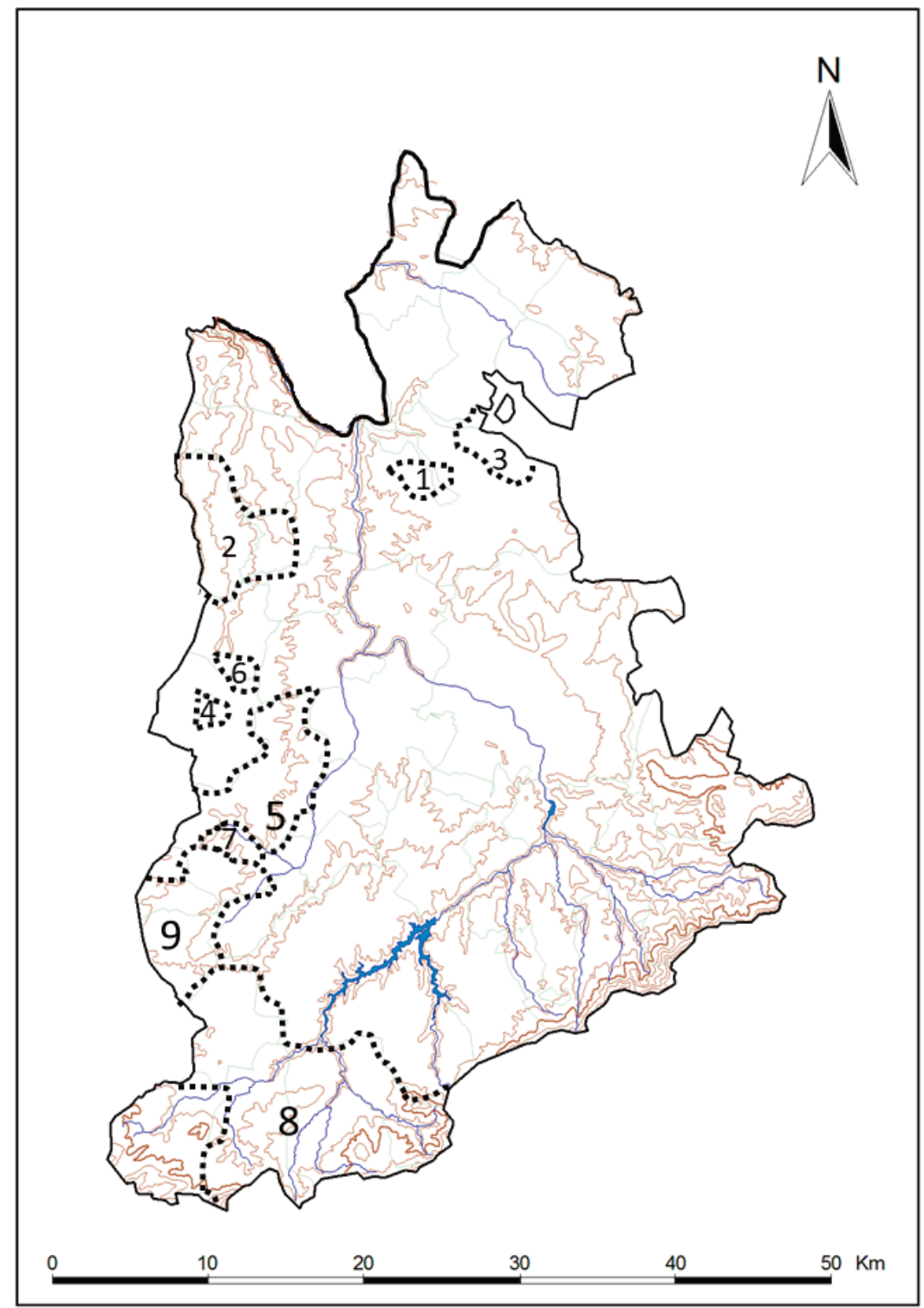

Balborraz; 2) Campo de Argañán (Villar de Ciervo-Aldea del Obispo-Villar de la Yegua-Mezquita); 3) Campo de Carniceros; 4) Dehesa del Águila; 5) Espeja-El Alcornocal; 6) La Mimbre; 7) Las Mohedas; 8) Robledo; 9) Valdeazaba (Ituero de Azaba-La Alamedilla-La Alberguería de Argañán). No localizados: Sotalvo y Valmanganiello-Valdemuelas.

Fuente: Elaboración de Iñaki Martín Viso. 
El Villar. Incluso en este caso, queda reflejada claramente la ausencia de títulos de propiedad. Esta situación tenía su plasmación en 1455, cuando se señalaba que Ciudad Rodrigo tenía devasos en su ejido (es decir, en su espacio de uso mancomunal asociado a su condición de asentamiento y no como villa), «de muy luengos tiempos desta parte, pero solicitaba que fueran apeados porque la memoria es deleznable e asy mesmo porque algunos de los que saben los terminos e mojones falleçen de la presente vida e porque otros que vienen lo sepan» ${ }^{1}$. Aunque se han conservado varias sentencias de finales del siglo XIV y del siglo $\mathrm{xV}$ en las que se recogía la condición de devaso de determinados lugares, parece que la costumbre seguía siendo, si no la única, al menos la principal fuerza que aseguraba los usos colectivos. Pero, como se ha advertido, por encima de ellos se fue generando un derecho concejil, lo que explicaría el interés creciente por parte del Concejo por reivindicar su posesión frente a posibles acciones de comunidades campesinas y elites urbanas tendentes a erosionar esos espacios con recursos colectivos (Monsalvo, 2007: 167-169; Luchía, 2008). Se estaba produciendo una transformación en el significado de los devasos al convertirse en un eje principal de la acción concejil. Esta "politización» de los espacios mancomunales se encontraba en el centro de la construcción de la autoridad del Concejo, que se convirtió en valedor de estos usos, a pesar de que de ellos se seguían beneficiando sobre todo los comarcanos.

La reclamación de los baldíos como concejiles generaba una propiedad comunal sustentada en el derecho, una herramienta que se manifestó útil para hacer frente a determinadas amenazas o que quizás fuera usada para reforzar la autoridad concejil sobre la Tierra. Sin embargo, no eliminaba la necesidad de establecer estrategias de reclamación basadas en la costumbre o en el ritual y que eran reconocidas por los habitantes más cercanos. Una situación que podemos examinar en el caso del ejido de Ciudad Rodrigo, un espacio emplazado en torno a la villa que se extendía fundamentalmente hacia el norte, en dirección a las sierras de Torralba y de la Perronilla, las cuales separan la cubeta de Ciudad Rodrigo de las penillanuras situadas hacia el este. Como indica su condición de ejido, se definía como un área de uso colectivo, en la que se identificaban una serie de espacios más reducidos y etiquetados como devasos en el siglo xv, los cuales coexistían con una serie de prados amojonados de uso particular. Puede entenderse este sistema como la traslación al caso de Ciudad Rodrigo del modelo comarcano, pero aplicado a los habitantes de la villa y de algunas alquerías que había a su alrededor. Al igual que en el resto de los devasos, estaban reservados al aprovechamiento colectivo por parte de los habitantes de la villa, fundamentalmente para la obtención de leña y para el pasto del ganado, mientras se guardaban los prados amojonados y las tierras de siembra ${ }^{2}$. Una ordenanza de la

1. Archivo Municipal de Ciudad Rodrigo (AMCR), 335-6-0, fol. 2r.-v.

2. «para que los vecinos e moradores de la dicha Çibdat los puedan paçer e cortar e rroçar e coger 
villa de 1434 prohibía la introducción de más de cien cabezas, entre ovejas, carneros y cabras (Barrios, Monsalvo \& Ser, 1988: doc. 251), una normativa que debía aplicarse seguramente también en el ejido y que nos habla del tipo de ganado más frecuente. Esta zona fue objeto de varios apeos referidos específicamente a algunos devasos ante la presión por parte de individuos que querían hacerse con su control y eliminar así el carácter colectivo. Así sucedía con Tejares, que, tras una pesquisa, fue declarado devaso y se obligó a María Sánchez, viuda del regidor Fernán García, a devolver su control al Concejo en 1434. La sentencia fallaba que Tejares era «termino conçegil, devaso de la dicha çibdat, por lo que los vezinos de la dicha çibdat lo puedan paçer con sus ganados por término conçegil, devaso de la dicha çibdat, guardando panes e vinnas labradas e guardando huertas e prados amojonados» (Barrios, Monsalvo \& Ser, 1988: doc. 245). Resulta interesante advertir cómo se equiparaba el concepto de devaso con el de concejil, por lo que había producido una identificación entre ambos significados. Pero también aparecen como usurpadores, desde la óptica del Concejo mirobrigense, el cabildo de la catedral de Ciudad Rodrigo en Serranos o la Orden del Pereiro en San Giraldo (ibid.: docs. 233, 239; Bernal, 1990: 149-151). Esta intervención concejil, especialmente relevante en los años treinta del siglo XV, quizás no fuera solo consecuencia de una presión externa sobre los espacios de uso colectivo, sino que pudo ser el resultado de un interés por afirmar el control sobre esos devasos y, en definitiva, por crear un nuevo statu quo. Es significativo el papel de las elites y de algunas importantes instituciones, que quizás pretendían formar una propiedad específica, pero que también pudieron disfrutar de derechos superiores de salvaguarda de estos bienes colectivos en competencia con el Concejo.

En cualquier caso, las sentencias marcaron un hito al transformar un uso consuetudinario en un derecho jurídico, que recaía en el Concejo en tanto que institución que articulaba al conjunto de los vecinos, condición necesaria para beneficiarse del aprovechamiento de los devasos. En 1455 se produjo una nueva oleada de apeos, una vez ya afirmado el dominio concejil, con el objeto de fijar claramente los límites espaciales de los devasos del ejido, evitando así, como se decía anteriormente, la fragilidad de la memoria humana. Pero en el nivel relacionado con los mecanismos de reclamación extrajurídicos, amparados en un conocimiento consuetudinario, llama la atención la utilización de elementos asociados con la religión. Uno de los indicios es la presencia de algunos hagiotopónimos que designaban a ciertos espacios de uso colectivo. En el caso del ejido de Ciudad Rodrigo, vemos la presencia de San Giraldo (Barrios, Monsalvo \& Ser, 1988: doc. 239) y la ya referida a San Martín; en la toponimia actual se encuentra también San Agustín. Es cierto que el número es reducido en relación con el número de devasos conocidos, pero no deja de tener una clara significación, porque la adopción quizás deba 
relacionarse con mecanismos de reclamación sobre tales áreas que remitían a una cierta sacralización, rememorando la presencia de algún tipo de santuario. En realidad, este mecanismo pudo haber estado más extendido de lo que parece. La ya citada elevada cifra de parroquias abandonadas en Ciudad Rodrigo que consigna Antonio Sánchez Cabañas (2001: 157-159) hacia 1627 y la dificultad de aceptar que todas ellas fueran en realidad iglesias parroquiales quizás sea un reflejo de la existencia de una serie de espacios a los que se reconocía una cierta sacralidad, quizás simplemente a través de hagiotopónimos o incluso con algún tipo de construcción, a tenor de las frecuentes menciones a paredones.

\section{FIGURA 5}

\section{El ejido de Ciudad Rodrigo y sus devasos en el siglo xv}

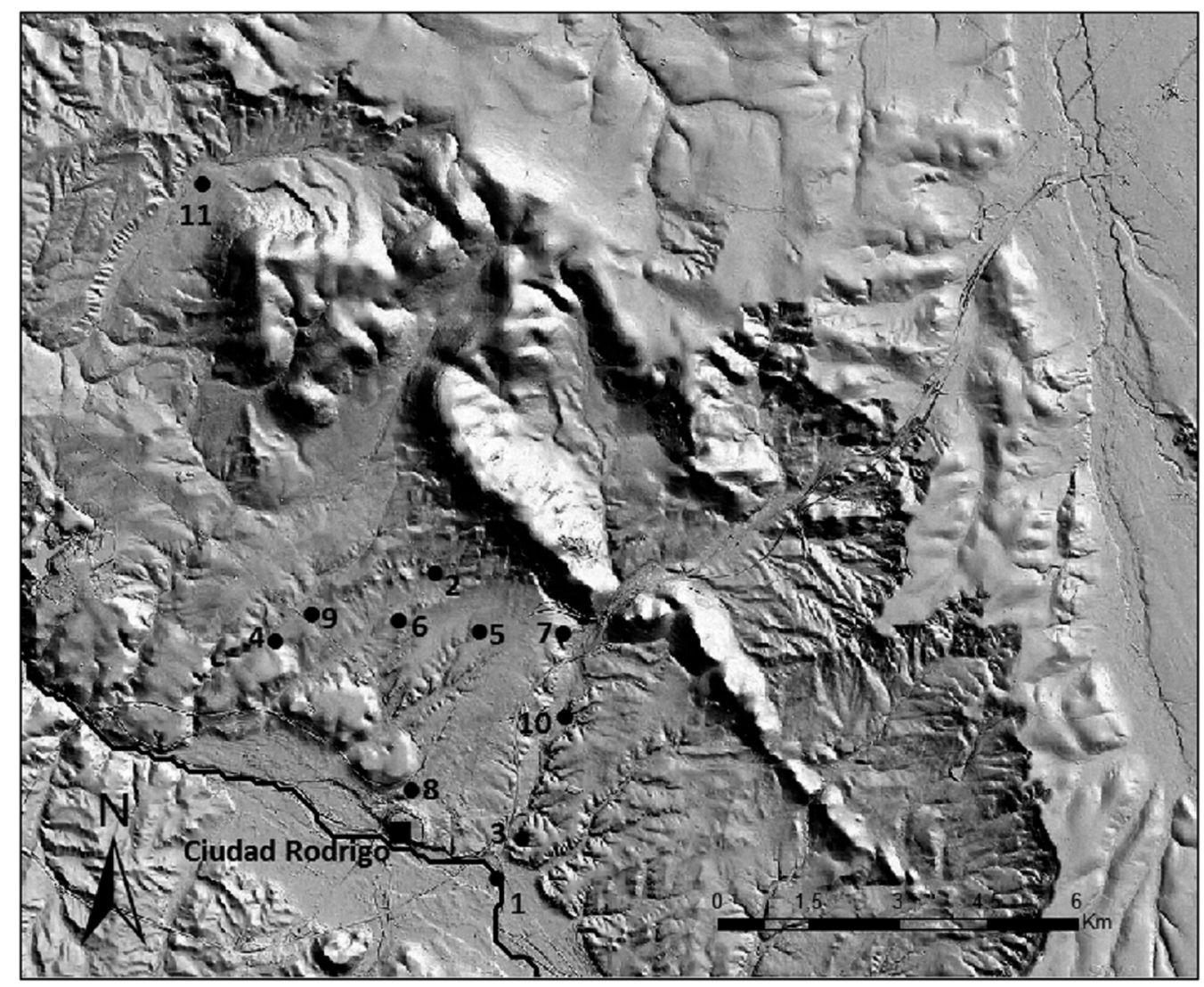

1) Cantarranas; 2) Capilla; 3) Carazo; 4) Castellanos; 5) Hamuxe (La Muge); 6 Pero Pulgar; 7) San Giraldo; 8) San Martín; 9) Serranos; 10) Tejares; 11) Valdenovillos. No localizados: Cortecillos, Cuesta del Obispo y Meleros (Dibujo y diseño de Javier Gómez Gómez). 


\section{FIGURA 6}

\section{La Sacristía (Villar de Ciervo)}

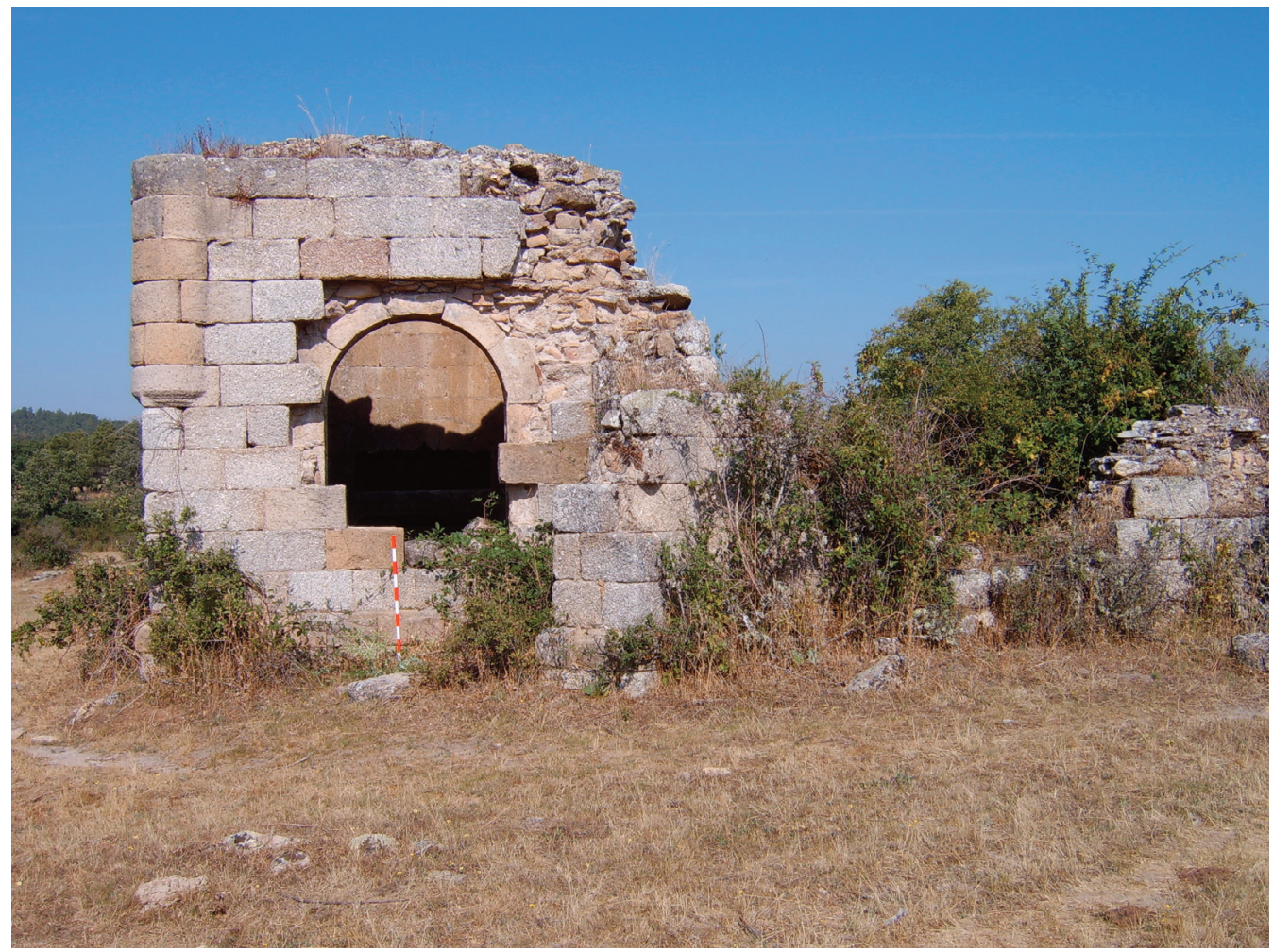

Fuente: Fotografía de Iñaki Martín Viso.

En tal sentido, cobra especial importancia el lugar llamado Capilla de la Sierra, situado en la actual pequeña alquería de Capilla, a unos cinco kilómetros al norte de Ciudad Rodrigo y cerca de la sierra de Torralba. Sabemos que este lugar era uno de los devasos del ejido de Ciudad Rodrigo. En 1398, se indicaba que sus prados estaban bajo control concejil para que en sus pastos pudieran pacer los ganados de los vecinos de Ciudad Rodrigo (Barrios, Monsalvo \& Ser, 1988: docs. 44, 45). En 1434, al calor de una serie de sentencias judiciales que establecieron el control concejil sobre los devasos del entorno de la villa, se estableció de nuevo el carácter de "termino conçegil e devaso» de Capilla, aunque se recogía la existencia de unos prados que estaban en manos de Fernando Nieto, vecino de Ciudad Rodrigo, quien parece haber intentado hacerse con el control de todo el lugar (Barrios, Monsalvo \& Ser, 1988: doc. 212). En relación con esa sentencia, se hizo un detallado apeo del lugar a cargo del juez Gonzalo Rodríguez de Madrigal. Se trata de un cuaderno de 101 folios donde se definen los términos de dicho lugar en el que se afirma 
«que el termino de Capilla, que esta alrededor de una iglesia nominada de Capilla, era devaso e conçegil» ${ }^{3}$. Este dato es de enorme interés, porque evidencia que el lugar, aunque careciese de un hagiotopónimo, se definía por la presencia de un edificio religioso, que no era una parroquia. Una circunstancia que también quedó reflejada en 1455 cuando, en el marco de los apeos realizados para renovar los mojones y fijar definitivamente los devasos del ejido, se declaró que Capilla era «devaso e conçegil e valdio e no tener termino alguno sobre si, e que los vecinos e moradores de la dicha çibdat lo pueden comer e coman e pastan con sus ganados e beuan las aguas e corten la lenna en la posesyon vel ius del dicho logar e termino» ${ }^{4}$. En ese documento, se citan una serie de prados que deben guardarse y se menciona un "plado de la iglesia». Por desgracia, no se conserva ninguna evidencia material de la presencia de esa iglesia en la actualidad. Sin embargo, se conoce la presencia de restos constructivos, en concreto tejas y ladrillos, así como cerámicas, en el cercano lugar de El Campanario de Santa Marina, por lo que se ha planteado la presencia de algún tipo de edificación sin una cronología segura ${ }^{5}$. Podría tratarse de una construcción semejante a la que se describía en el término de Capilla asociada además a la presencia de un hagiotopónimo, Santa Marina, en una zona igualmente definida por la presencia de devasos cercanos.

Esta relación entre devasos y edificaciones religiosas de tipo ermita o capilla, es decir, construcciones religiosas no parroquiales, no es única del ejido de Ciudad Rodrigo.También aparece en otros puntos, como ocurre en Alba de Yeltes, donde en 1414 el corregidor de Ciudad Rodrigo, Gómez Arias, ordenó que se reintegrase como devaso la nava de Medinilla, ocupada ilegalmente por Sancho Gómez, y que se encontraba en el lugar de Alba deYeltes. Para reafirmar la sentencia, el corregidor procedió al amojonamiento junto a una serie de vecinos del lugar y de las aldeas de Puebla de Yeltes y Sepulcro-Hilario, en lo que parece ser una evidencia de usos comarcanos. Resulta interesante que el recorrido se inició con la revisión de los mojones «que antiguamente fueran puestos desde la iglesia que dizen de Sant Andres de Boçedilla» (Barrios, Monsalvo \& Ser, 1988: doc. 73). No se ha podido identificar este lugar, que desde luego no era la parroquia del lugar de Alba de Yeltes, que habría sido señalada como tal. De nuevo se observa esa relación entre devasos y construcciones religiosas que parece ser una parte importante de los paisajes comunales. Otro ejemplo procede del lugar de La Sacristía, en la dehesa de Camporredondo (Villar de Ciervo), donde, junto a una pequeña necrópolis de 11 tumbas excavadas en la roca de origen altomedieval, se conserva una construcción de tipo eclesiástico y de estilo gótico, por tanto, con una datación tardomedieval (Martín Viso, 2012: 179) (Fig. 6). En

3. AMCR, I. E. 2.3.1.

4. AMCR, 335-4-0, fol. 6v.

5. Según la ficha correspondiente del Inventario Arqueológico de la Provincia de Salamanca. 
este caso, sin embargo, no tenemos una plena constancia de la existencia de un devaso, aunque esta zona del Campo de Argañán aparece en 1376 como uno de los sectores donde ese modelo de gestión del espacio agrario se conservaba con mayor fuerza. Todos estos ejemplos estarían poniendo de relieve la presencia de estrategias de reclamación de derechos que utilizaban elementos de carácter religioso que sin duda tenían un especial valor para las gentes de la zona, aunque no implicasen a la altura del siglo XV un reconocimiento oficial como lugares de culto, ni mucho menos su integración en el sistema parroquial. Pero llama la atención cómo en algunos puntos, como San Martín, pudo haber alguna conexión entre espacios funerarios, lugares dotados de hagiotopónimos -y quizás con una construcción a tenor de lo que registraba Sánchez Cabañas-y áreas de devaso, una conexión menos nítida en La Sacristía-Camporredondo. Es evidente que los casos no son numerosos, pero eso podría responder a que era una estrategia más dentro de un amplio conjunto de posibilidades desplegadas por los habitantes locales. En cualquier caso, la información pone de relieve que, más allá de los hagiotopónimos, existían también construcciones asociadas a rituales colectivos de carácter cristiano.

\section{RECLAMACIONES CAMPESINAS Y ESTRATEGIAS CONCEJILES}

En los siglos bajomedievales se produjo la consolidación del concepto de devaso a través de su fijación jurídica como bien concejil gracias a una serie de sentencias producto de un marco de tensiones sobre los derechos de uso. Pero, al mismo tiempo, subsistían paralelamente prácticas de reclamación de derechos basadas en el conocimiento local y probablemente previas a la inserción en el marco concejil. Su presencia denotaba que los espacios de uso colectivo estaban dentro de una cosmovisión más amplia referida a la propia percepción de la moral social y política por parte de las poblaciones campesinas. Nada de ello impedía la intervención de poderes externos, en especial como garantes y defensores últimos de estos usos. Las dataciones procedentes de la tumba de la calle de Fray Diego, número 15, podrían indicar que estamos ante prácticas previas a la creación de la villa como ente jurídico. En esos momentos, la comunidad asentada en Ciudad Rodrigo pudo haber desarrollado mecanismos de aprovechamiento colectivo de los recursos semejantes a los que quizás también se daban en ámbitos rurales. No obstante, carecemos de una batería de datos que permita avanzar de momento en esa hipótesis, aunque la temprana presencia de los mancomunales y algunos registros polínicos serían indicios que irían en esa misma línea. En cualquier caso, estas prácticas son difíciles de observar porque quedaron obliteradas por la implantación de nuevos modelos sociales y políticos, representados por el Concejo y las parroquias, que construyeron nuevos paisajes. Nos quedan solo retazos de aquella realidad. 
Se trataba de prácticas consuetudinarias, regidas por la costumbre, no por títulos jurídicos recogidos por escrito, ya que «los comunales más que bienes en sí, son derechos de aprovechamiento» (Asenjo, 1986: 174). Era necesario que esas zonas estuvieran identificadas y, para ello, se crearon marcadores físicos que dotaban de significado a los paisajes comunales. El conocimiento local era la base, pero también una ritualidad a través de la cual se plasmaban -tal vez cíclicamente- esos derechos sobre espacios específicos. En el caso de Ciudad Rodrigo, quizás los enterramientos debieron ser una de las posibles fórmulas usadas en el siglo XI y comienzos del XII. En estos momentos, no había eclosionado todavía el cementerio parroquial y eran las familias y las comunidades las que gestionaban los espacios funerarios (Zadora-Rio, 2003; Lauwers, 2005). El resultado era una pluralidad de situaciones, que respondían a impulsos locales. En este contexto, la memoria de los fallecidos podía servir como un medio para reclamar derechos sobre el terreno (Parker Pearson, 1999: 132-136). Los datos permiten lanzar la hipótesis de que así sucedía en Ciudad Rodrigo con respecto a las áreas de uso comunal, como ya se ha probado en el caso de la sierra de Ávila (Blanco \& Martín Viso, 2016). La memoria de los antepasados y el enterramiento continuado en esos lugares (la tumba examinada contenía restos de tres individuos) eran elementos asociados a una ritualidad que podría haber tenido como uno de sus objetivos la reclamación de estos derechos y que habría fundamentado el conocimiento local. Se estaría relacionando esa reclamación de derechos con escenarios dotados de un significado simbólico y posiblemente religioso, aunque no necesariamente eclesiástico. Ahora bien, no ha sido posible identificar de momento una situación semejante en otros devasos rurales, lo que podría ser un indicio de que había diversas estrategias o quizás sea necesaria una investigación más específica. Pero también puede ser la consecuencia de la dificultad de observar prácticas no fijadas por escrito y espacios no monumentalizados. Es una reconstrucción hipotética, pero no por ello menos factible, puesto que parece haberse verificado en otras zonas cercanas.

La implementación de los cementerios parroquiales imposibilitó el mantenimiento de tradiciones funerarias locales y estimuló una clara homogeneización de esas prácticas, lo que seguramente explique el abandono del uso funerario del área del teso de San Martín. Se produjo así una transformación, pero se mantuvo el sentido religioso. Una forma de dotar de un aura sacra pudo haber sido el uso de hagiotopónimos que caracterizarían a algunos de estos espacios, posiblemente asociados a memorias sobre su pasado, quizás pequeñas iglesias. Se salvaguardaba así el vínculo simbólico y religioso, que reforzaba los derechos de acceso y la gestión de esos comunales. Pero lo que se ha podido observar es que en algunos casos se construyeron efectivamente edificaciones a las que se concedía un carácter religioso. El ejemplo de Capilla de la Sierra lo pone de relieve y muestra su existencia ya en el siglo XV, pero quizás ya funcionaba con anterioridad. También se han citado los casos de El Campanario de Santa Marina o San Andrés de Bocedillas. Pero ¿qué 
eran estas iglesias? Es posible que sirvieran como puntos de reunión en el que se celebraban rituales religiosos, una fórmula a través de la cual se reclamaban los derechos sobre esos lugares, que tenían una posición central con respecto a los devasos. Ya se ha advertido cómo la profusión de parroquias abandonadas que refiere Sánchez Cabañas en el siglo XVII puede interpretarse como el recuerdo, al menos parcial, de ese tipo de construcciones; su caracterización parroquial, es decir, como iglesias diocesanas relacionadas con la administración de sacramentos, respondía a la mentalidad de un canónigo de la época barroca que no podía pensar en otros términos. Todo ello nos lleva a la frecuente presencia de ermitas en el paisaje rural de buena parte del centro peninsular. Algunos trabajos han planteado cómo tenían un papel relevante en la creación de identidades comarcales de origen altomedieval (Vigil-Escalera, 2019). En tal sentido, podría haber una conexión con prácticas mancomunales. Pero la información es muy escasa; los datos sobre Ciudad Rodrigo parecen indicar que este tipo de situaciones se dio, al menos en algunas comarcas, ya en la Baja Edad Media y que solo la transformación en ermitas en época moderna permitió la preservación de algunas de estas construcciones. No obstante, el ejemplo mirobrigense no es único. Se ha advertido también de su presencia en los territorios boscosos de Sepúlveda -caracterizados por la abundancia de espacios de recurso colectivo- en los siglos XIII y XIV, incluidos los límites de su fuero romanceado (Clément, 1994: 258-260). Aunque este dato se ha interpretado como la plasmación de la búsqueda del desierto por los religiosos, situándose en zonas poco pobladas, y también con la moralización de las costumbres de las gentes que habitaban esas áreas, podría tratarse en realidad del mismo mecanismo que aquí hemos tratado: un medio para reforzar derechos de uso previos a la construcción del Concejo y sustentados en prácticas consuetudinarias. Se trataría de un proceso que se observa antes en Sepúlveda, pero que remite sin duda al periodo posterior a la implantación del modelo parroquial. Por consiguiente, las poblaciones locales habrían adaptado y transformado sus estrategias de reclamación, para lo que utilizaron recursos de carácter religioso que no solo fueron vías de dominio social, sino también herramientas que podían ser incluidas en las reivindicaciones y culturas políticas campesinas, como otros estudios ya han señalado (Alfonso, 2010).

Por encima de esta articulación local se situaba el dominio concejil. No eran dos realidades contrapuestas, ya que el papel del Concejo era fundamentalmente el de salvaguardar los derechos de uso, por lo que no había una contradicción. En el caso del ejido de la villa, es muy probable que haya sido desde el periodo previo a la creación de la propia villa el espacio donde se encontraban las áreas de recurso colectivo, una suerte de gran devaso de la población de Ciudad Rodrigo, dividido a su vez en devasos menores. En cambio, el proceso de conversión de los devasos en concejiles fue un medio de afirmación de la villa sobre la Tierra. En la encuesta de 1376 se observa una divergencia entre los testimonios de los habitantes de la Tierra y la sentencia en la que se habla ya de «devaso del 
conçejo de la dicha çibdad» (Barrios, Monsalvo \& Ser, 1988: doc. 20). Es a partir de entonces cuando se consolida la posición del Concejo, aprovechando el conflicto que le permitía configurar y consolidar un nuevo marco de actuación, como también se observa en otras áreas peninsulares (Stagno, 2017). En el siglo XV, se lleva a cabo una política de defensa de los intereses concejiles sobre esas áreas de uso mancomunal, que parece sobre todo buscar la creación de títulos jurídicos, mediante sentencias. Se solventaba así la ausencia de una base jurídica y, de alguna manera, los usos se convertían en propiedad y se aseguraba su control. Esta situación se produjo en el siglo XV y se sustentaba en la «politización» de los propios devasos, convertidos en uno de los ejes principales de la acción concejil. La estrategia de reclamación fue diferente: los lugares se amojonaron, tal y como se observa en 1455, diferenciando los devasos de los prados que deben guardarse.

\section{CONCLUSIONES}

$\mathrm{Al}$ comienzo de este trabajo nos hacíamos una serie de preguntas sobre las estrategias de reclamación de los espacios colectivos. El análisis del caso mirobrigense ha permitido plantear una posible interpretación a partir de algunos datos. No se trata de una reconstrucción exenta de numerosos problemas relacionados con la evidencia ni de un cierto grado de especulación, pero, a pesar de que estamos ante un nudo crucial de la articulación de las sociedades locales, las informaciones son escasas por su propia naturaleza. Cabe añadir dos factores más: la progresiva obliteración por otras prácticas y la inexistencia de un patrón único. En el caso de estudio, pueden interpretarse los datos al calor de la relevancia de determinados referentes funerarios, no necesariamente ligados a la Iglesia oficial. En tal sentido, es necesario subrayar el papel de los marcadores físicos que visibilizaban en el paisaje la reclamación colectiva de los usos. En las sociedades medievales los objetos y los monumentos actuaban como elementos básicos de la memoria social, y permitían recordar historias que se relacionaban con significados socioculturales muy presentes en las comunidades locales (Moreland, 2003: 39-41).

En cambio, durante la Baja Edad Media parece haberse producido un proceso de incorporación de esos espacios y usos colectivos preexistentes al Concejo, lo que posibilitó la implementación del dominio concejil en amplias áreas de la Tierra. Una posible explicación es que la salvaguarda de estos usos, entendidos ahora como bienes concejiles, se convirtió en un instrumento básico del discurso político en el ámbito concejil. Carecemos de una documentación legal que refiera el paso al dominio concejil, probablemente porque no se efectuó a través de un acto sancionado jurídicamente. Las estrategias de legitimación fueron el concepto de propiedad concejil y el amojonamiento. Sin embargo, la intervención de los propietarios de la villa en los devasos de la Tierra continuó siendo poco 
frecuente, mientras que los usos descansaban en los propios comarcanos. Más allá de la propiedad concejil, puede plantearse un concepto local, campesino, sobre estos recursos, que hundía sus raíces en tiempos pasados y cuyos ecos interpretamos. Formaban parte de la organización de los espacios locales y de sus habitantes desde antes de la afirmación de la villa concejil, sin que por ello deba verse su articulación como una reminiscencia de un pasado prehistórico inventado (Monsalvo, 2007: 163). La hipótesis de este trabajo es que los concejos, y en este caso el de Ciudad Rodrigo, asumieron el papel de salvaguarda, pero, al definirlos en términos de propiedad concejil, los modificaron y abrieron la puerta a otros cambios. No obstante, pervivieron unos paisajes definidos por los espacios comunales en los que la memoria local y una cierta dosis de sacralización dotaban al conjunto de un significado que incidía en las prácticas cotidianas de los habitantes.

\section{AGRADECIMIENTOS}

Este trabajo se ha realizado dentro del proyecto de investigación «Formación y dinámica de los espacios comunales ganaderos en el Noroeste de la Península Ibérica medieval: paisajes e identidades sociales en perspectivas comparadas» (HAR2016-76094-C4-4-R). Agradecemos a Tomás Domínguez Cid, por su amabilidad a la hora de ayudarnos a consultar los fondos del Archivo Municipal de Ciudad Rodrigo, a Javier Gómez Gómez por su ayuda en la realización de las figuras, a José Ignacio Martín Benito y Álvaro Carvajal Castro por haber leído y comentado un primer borrador de este texto, y a los tres informantes anónimos de la revista Historia Agraria por sus sugerencias y reflexiones que han ayudado a mejorar el artículo.

\section{REFERENCIAS}

Alacet (2006). Excavaciones arqueológicas previas en la iglesia de Santa Elena de Ledesma (Salamanca).Valladolid: [Informe inédito].

Alfonso, M. I. (2010). Iglesias rurales en el norte de Castilla: Una dimensión religiosa de las luchas campesinas durante la Edad Media. En R. RoBledo \& R. GARRABOU (Eds.), Sombras del progreso: Las huellas de la historia agraria (pp. 27-65). Barcelona: Crítica.

Argente del Castillo, C. (1991). La ganadería medieval andaluza, siglos XIII-XVI: Reinos de faén y Córdoba. Jaén: Diputación Provincial de Jaén.

Asenjo, M. (1986). Segovia: La ciudad y su tierra a fines del medievo. Segovia: Diputación Provincial de Segovia. 
AsEnjo, M. (1999). Espacio y sociedad en la Soria medieval (siglos XIII-XV). Soria: Diputación Provincial de Soria.

Ayala, C. DE (Comp.) (1995). Libro de Privilegios de la Orden de San Fuan de Ferusalén en Castilla y León (siglos XII-XV). Madrid: Universidad Complutense de Madrid. BARRIOS, A. (1983). Estructuras agrarias y de poder en Castilla: El ejemplo de Ávila (10851320). Salamanca: Universidad de Salamanca/Institución Gran Duque de Alba.

BARrios, A. (2002). En torno a los orígenes y la consolidación de la diócesis civitatense. En Actas del Congreso de Historia de la Diócesis de Ciudad Rodrigo (pp. 169-210). Ciudad Rodrigo: Diócesis de Ciudad Rodrigo.

Barrios, A., Monsalvo, J. M. \& Ser, G. Del (1988). Documentación medieval del Archivo Municipal de Ciudad Rodrigo. Salamanca: Diputación Provincial de Salamanca.

Bernal, A. (1990). El Concejo de Ciudad Rodrigo y su tierra durante el siglo XV. Salamanca: Diputación Provincial de Salamanca.

Blanco, A. et al. (2015). Medieval Landscapes in the Spanish Central System (4501350): A Paleoenvironmental and Historical Perspective. Fournal of Medieval Iberian Studies, 7 (1), 1-17.

Blanco, A. \& MARTín Viso, I. (2016). Tumbas, parroquias y espacios ganaderos: Configuración y evolución del paisaje medieval de la sierra de Ávila. Historia Agraria, (69), 11-41. http://www.historiaagraria.com/FILE/articulos/HA69_blanco_martin2.pdf

CABRERA, E. (1978). Usurpación de tierras y abusos señoriales en la sierra cordobesa durante los siglos XIV y Xv. En Actas del I Congreso de Historia de Andalucía 2: Andalucía medieval (pp. 33-83). Córdoba: Monte de Piedad y Caja de Ahorros de Córdoba.

CARMONA, M. A. (1995). Usurpaciones de tierras y derechos comunales en Sevilla y su «tierra» durante el siglo XV. Madrid: Ministerio de Agricultura, Alimentación y Medio Ambiente.

Carvajal, A. (2017). Prácticas colectivas y gestión de los espacios agrarios en la Alta Edad Media: Una perspectiva comparada desde Irlanda y el noroeste de la península ibérica. Historia Agraria, (73), 151-183.

Centeno, I. (2018). Ciudad Rodrigo en época posimperial: Revisión de un falso vacío. En I. MARTín VISO (Ed.), Fortificaciones, poblados y pizarras: La Raya en los inicios del Medievo (pp. 167-176). Ciudad Rodrigo: Ayuntamiento de Ciudad Rodrigo.

Clément, V. (1994). La forêt et les hommes en Castille au XIII siècle: L'exemple du territoire de Sepúlveda. Mélanges de la Casa de Velázquez, 30 (1), 253-274.

CurTis, D. R. (2016). Did the Commons Make Medieval and Early Modern Rural Societies More Equitable?: A Survey of Evidence from across Western Europe, 13001800. Fournal of Agrarian Change, 16 (4), 646-664.

DALgLish, C. (2009). Understanding Landscape: Inter-Disciplinary Dialogue and the Post-Medieval Countryside. En A. J. Horning \& M. Palmer (Eds.), Crossing Paths 
or Sharing Tracks?: Future Directions in the Archaeological Study of Post-1550 Britain and Ireland (pp. 233-254). Woodbridge: Boydell \& Brewer.

De Keyzer, M. (2018). Inclusive Commons and the Sustainability of Peasant Communities in the Medieval Low Countries. London: Routledge.

De Moor, T. (2015). The Dilemma of the Commoners: Understanding the Use of Common-Pool Resources in Long-Term Perspective. Cambridge: Cambridge University Press.

De Moor, M., ShaW-TAYlor, L. \& Warde, P. (2002). The Management of Common Land in North West Europe, c. 1500-1850. Turnhout: Brepols

Diago, M. (1990). Aprovechamiento de baldíos y comunales en la Extremadura soriana a fines de la Edad Media. Anuario de Estudios Medievales, (20), 413-435.

EsCALONA, J. (2004). Family Memories: Inventing Alfonso I of Asturias. En I. Alfonso, H. Kennedy \& J. Escalona (Eds.), Building Legitimacy: Political Discourses and Forms of Legitimation in Medieval Societies (pp. 223-262). Leiden: Brill.

Escalona, J. (2019). Dense Local Knowledge: Grounding Local to Supralocal Relationships in Tenth-century Castile. En J. Escalona, O. VÉSTEINSSON \& S. Brookes (Eds.), Polity and Neighbourhood in Early Medieval Europe (pp. 351-379). Turnhout: Brepols.

García Andreva, F. (2010). El Becerro Galicano de San Millán de la Cogolla: Edición y estudio. Logroño: Fundación San Millán de la Cogolla.

GARCíA DE CORTÁZAR, J. A. (1988). La sociedad rural en la España medieval. Madrid: Siglo XXI.

GARCÍA HERNÁNDEZ, J. I. (2018). Control arqueológico en relación al proyecto básico y de ejecución de vivienda unifamiliar en c/ Fray Diego 15 de Ciudad Rodrigo (Salamanca) (MU-193/2018). Salamanca: [Informe inédito].

García Oliva, M. D. (2017). Usurpaciones de tierras comunales en el término de Plasencia a fines de la Edad Media. Studia Historica. Historia Medieval, 35 (1), 157-178.

Genicot, L. (1993). Comunidades rurales en el occidente medieval. Barcelona: Crítica.

Gil Fernández, J., Moralejo, J. L. \& Ruiz de la PeÑa, J. I. (1985). Crónicas asturianas. Oviedo: Universidad de Oviedo.

GoldsteIn, L. (1981). One-Dimensional Archaeology and Multi-Dimensional People: Spatial Organization and Mortuary Analysis. En R. CHAPMAN, I. KInNEZ \& K. RANDSBorg (Eds.), The Archaeology of Death (pp. 53-69). Cambridge: Cambridge University Press.

GonZÁlez Echegaray, J. (2000). El Colegio de la Compañia de fesús en Salamanca (Universidad Pontificia): Arqueología e historia. Salamanca: Universidad Pontificia de Salamanca.

Guadalupe, M. L. et al. (2010). Colección documental del Archivo de la Catedral de Salamanca I: 1098-1300. León: Centro de Estudios e Investigación «San Isidoro». 
JARA, J. A. (2001-2002). "Que memoria de onbre non es en contrario»: Usurpaciones de tierras y manipulación del pasado en la Castilla urbana del siglo xv. Studia Historica. Historia Medieval, (20-21), 73-104. http://revistas.usal.es/index.php/Studia_H_Hist oria_Medieval/article/view/4512/4529

JiMÉNEZ DE RADA, R. (1987). Historia de rebus Hispanie sive Historia Gothica. Turnhout: Brepols.

LARREA, J. J. (2003-2004). Aldeas navarras y aldeas del Duero: Notas para una propuesta comparada. Edad Media. Revista de Historia, (6), 159-181. https://dialnet.unirioja.es/servlet/articulo?codigo $=958076$

LAUWERs, M. (2005). Naissance du cimetière: Lieux sacrés et terre des morts dans l'occident médiéval. Paris: Aubier.

Lucas, M. (1997). La documentación del tumbo A de la catedral de Santiago de Compostela: Estudio y edición. León: Centro de Estudios e Investigación «San Isidoro».

LuCHÍA, C. (2008). Los pleitos por los términos comunales en el concejo de Ciudad Rodrigo en la Baja Edad Media. Historia, Instituciones, Documentos, (35), 269-290. https://revistascientificas.us.es/index.php/HID/article/view/4178/3626

Mattingly, D. (2008). Technological or Social Landmarks?: The Foggaras of the Garamants in Southern Lybia. En R. Compantangelo-Soussignan et al. (Eds.), Marqueurs des paysages et systems socio-économiques (pp. 127-134). Rennes: Presses Universitaires de Rennes.

Martín Benito, J. I. (2005). La iglesia de Ciudad Rodrigo. En Historia de las diócesis españolas 18: Iglesias de Ávila, Salamanca y Ciudad Rodrigo (pp. 323-566). Madrid: Biblioteca de Autores Cristianos.

Martín Martín, J. L. (1990). Evolución de los bienes comunales en el siglo xv. Studia Historica. Historia Medieval, (8), 7-46. https://revistas.usal.es/index.php/Studia H_Historia_Medieval/article/view/4388/4407

MARTín Viso, I. (2012). Enterramientos, memoria social y paisaje en la Alta Edad Media: Propuestas para un análisis de las tumbas excavadas en roca en el centro-oeste de la península Ibérica. Zephyrus: Revista de prehistoria y arqueología, (69), 165-187. https://revistas.usal.es/index.php/0514-7336/article/view/9036/9639

MARTínVISO, I. (2014). ¿Datar tumbas o datar procesos?: A vueltas con la cronología de las tumbas excavadas en la roca en la Península ibérica. Debates de Arqueología Medieval, (4), 29-65. http://www.arqueologiamedievaldebates.com/articulo$77 / \% \mathrm{C} 2 \% \mathrm{BFdatar}$-tumbas-o-datar-procesos?-a-vueltas-con-la-cronologia-de-las-tumbas-excavadas-en-roca-en-la-peninsula-iberica

Martín Viso, I. (2015). Después qu'esta ciudad fue destruyda: Ciudad Rodrigo y su comarca en la Alta Edad Media (siglos VI-XI). Ciudad Rodrigo: Centro de Estudios Mirobrigenses. 
MARTíN VISO, I. (2016). Comunidades locales, lugares centrales y espacios funerarios en la Extremadura del Duero alto medieval: Las necrópolis de tumbas excavadas en roca alineadas. Anuario de Estudios Medievales, 46 (2), 859-898.

Martín Viso, I. (2020). Territorios resilientes: Mancomunales y concejos en el sur del Duero durante la Edad Media.Vínculos de Historia, (9), 226-245.

Martín Viso, I. (en prensa). Orta fuit intemtio: Communities and Disputes in Northern Iberia ( $9^{\text {th }}-11^{\text {th }}$ Centuries). En G. BÜHrer-THIERRY $\&$ V. LorÉ (Eds.), Agir en commun durant le haut Moyen Age.

MARTín Viso, I. et al. (2017). La formación de un nuevo paisaje en el centro de la península ibérica en el periodo posromano: El yacimiento de La Genestosa (Casillas de Flores, Salamanca). Archivo Español de Arqueología, (90), 7-28.

MíngueZ FERNÁNDEZ, J. M. (1982). Ganadería, aristocracia y reconquista en la Edad Media castellana. Hispania, 42 (151), 341-354.

Monsalvo, J. M. (2001). Usurpaciones de comunales: Conflicto social y disputa legal en Ávila y su Tierra durante la Baja Edad Media. Historia Agraria, (24), 89-122. http://www.historiaagraria.com/FILE/articulos/HA24_monsalvo.pdf

Monsalvo, J. M. (2004). Aspectos de las culturas políticas de los caballeros y pecheros en Salamanca y Ciudad Rodrigo a mediados del siglo xv: Violencias rurales y debates sobre el poder en los concejos. En I. Alfonso, J. Escalona \& G. MARTín (Eds.), Lucha politica: Condena y legitimidad en la España medieval (pp. 237-296). Lyon: ENS.

Monsalvo, J. M. (2007). Comunidades de aldea, comunales de ciudad-y-tierra: Algunos aspectos de los aprovechamientos comunitarios en los concejos medievales de Ciudad Rodrigo, Salamanca y Ávila. En A. RodRíGuez López (Ed.), El lugar del campesino: En torno a la obra de Reyna Pastor (pp. 141-177). Valencia: Universitat de València. Monsalvo, J. M. (2010a). Paisaje agrario, régimen de aprovechamiento y cambio de propiedad en la Tierra de Ávila durante el siglo Xv: La creación del término redondo de Zapardiel de la Serrezuela. En J. M. Monsalvo, Comunalismo concejil abulense: Paisajes agrarios, conflicto y percepciones del espacio rural en la Tierra de Ávila y otros concejos medievales (pp. 19-112). Ávila: Diputación Provincial de Ávila/Institución Gran Duque de Alba.

Monsalvo, J. M. (2010b). Raíces sociales de los valores estamentales concejiles: La construcción de las mentalidades y culturas rurales de caballeros y pecheros (Ávila y su Tierra, siglos XIII-Xv). En J. M. Monsalvo, Comunalismo concejil abulense: Paisajes agrarios, conflicto y percepciones del espacio rural en la Tierra de Ávila y otros concejos medievales (pp. 251-319). Ávila: Diputación Provincial de Ávila/Institución Gran Duque de Alba.

Monsalvo, J. M. (2012-2013). Paisajes pastoriles y forestales en tierras salmantinas y abulenses: Aprovechamientos y cambios en los espacios rurales (ss. XII-Xv). Norba. Re- 
vista de Historia, (25-26), 105-147. https://dialnet.unirioja.es/servlet/ articulo?codigo $=5348365$

Moreland, J. (2003). Archaeology and Text. London: Duckworth.

Oosthuizen, S. (2013). Tradition and Transformation in Anglo-Saxon England: Archaeology, Common Rights and Landscape. London: Bloomsbury.

Ostrom, E. (1990). Governing the Commons: The Evolution of the Institutions of Collective Action. Cambridge: Cambridge University Press.

Parker Pearson, M. (1999). The Archaeology of Death and Burial. Stroud: Sutton.

PASTOR, R. (1980). Resistencias y luchas campesinas en la época del crecimiento y consolidación de la formación feudal: Castilla y León, siglos X-XIII. Madrid: Siglo XXI.

Plaza de Agustín, J. (2015). La usurpación de tierras comunales y baldíos en Guadalajara durante la segunda mitad del siglo Xv. Espacio, Tiempo y Forma. Historia Medieval, (28), 459-485.

Reglero de LA Fuente, C. M. (2015). La frontera del Duero: En los orígenes de las comunidades de villa y tierra. En M. Ríos SAloma (Ed.), El mundo de los conquistadores (pp. 665-686). Madrid: Sílex.

Rubio, R. (2015). Arqueología, paisaje y territorio post-romano: Las tumbas excavadas en roca en el occidente del campo de Ciudad Rodrigo (Salamanca). Ciudad Rodrigo: Centro de Estudios Mirobrigenses.

Sánchez Cabañas, A. (2001). Historia civitatense. Ciudad Rodrigo: Centro de Estudios Mirobrigenses.

SÁnchez-Oro, J. J. (1997). Orígenes de la iglesia en la diócesis de Ciudad Rodrigo: Episcopado, monasterios y órdenes militares (1161-1264). Ciudad Rodrigo: Centro de Estudios Mirobrigenses.

SAXE, A. (1971). Social Dimensions of Mortuary Practices in a Mesolithic Population from Wadi Halfa, Sudan. En J. A. Brown (Ed.), Approaches to the Social Dimensions of Mortuary Practices (pp. 39-57). Washington: Society for American Archaeology.

ScotT, J. C. (1976). The Moral Economy of the Peasant: Rebellion and Subsistence in Southeast Asia. New Haven:Yale University Press.

Silva, N. et al. (2006). Influence of Climate Change and Human Activities on the Organic and Inorganic Composition of Peat during the Little Ice Age (El Payo mire, W. Spain). The Holocene, 2 (8), 1290-1303.

STAGNO, A. (2017). Archeologia e storia di un spazio precario: Le culture temporanee tra pratiche collettive e appropriazione privata (Paesi Baschi, XV-XIX secolo). Quaderni Storici, (55), 499-533.

Thompson, E. (1995). Costumbres en común. Barcelona: Crítica.

Vigil-Escalera, A. (2019). Meeting Places, Markets, and Churches in the Countryside between Madrid and Toledo, Central Spain (c. AD 500-900). En J. EsCALONA, O.VÉs- 
TEINSSON \& S. BRookes (Eds.), Polity and Neighbourhood in Early Medieval Europe (pp. 173-202). Turnhout: Brepols.

VILLAR, L. M. (1986). La Extremadura castellano-leonesa: Guerreros, clérigos y campesinos (711-1252).Valladolid: Junta de Castilla y León.

Vivancos, M. C. (1988). Documentación del monasterio de Santo Domingo de Silos (9541254). Burgos: Garrido Garrido.

Wood, A. (2013). The Memory of the People: Custom and Popular Senses of the Past in Early Modern England. Cambridge: Cambridge University Press.

Zadora-Rio, E. (2003). The Making of the Churchyards and the Parish Territories in the Early Medieval Landscape of France and England in the $7^{\text {th }}-12^{\text {th }}$ Centuries: A Reconsideration. Medieval Archaeology, 47 (1). 1-19. 